\title{
The discounting water influence estimation on the results of the annual concentration calculation and runoff volume of the Pskem river biogenous substances
}

\author{
Alisher Fatxulloyev ${ }^{*}$, Jasurbek Hamroqulov, and Aziza Gafarova \\ Tashkent Institute of Irrigation and Agricultural Mechanization Engineers, Tashkent, Uzbekistan
}

\begin{abstract}
This article presents scientific research methods for assessing the average annual concentration of pollutants along the Pskem river. The analysis of existing calculation methods and assessed their errors are given. Extreme errors and errors in determining the average long-term concentration due to the lack of water content are analyzed. Recommendations to reduce possible errors due to neglect of water content in the absence of measured water flow rates are given.
\end{abstract}

\section{Introduction}

The development of industry and agriculture is inextricably linked with an increase in the amount of wastewater entering river waters and direct pollution of the river waters themselves. Therefore, since the middle of the last century, the problem of surface water quality has become more acute. At the same time, the role of scientific research in this direction is also growing.

In natural waters, nitrogen exists is in the form of dissolved free $\mathrm{N}_{2}$ molecules, dissolved gaseous compounds $\mathrm{NH}_{3}$, ions of mineral compounds: ammonium $\mathrm{NH}_{4}+$, nitrite $\mathrm{NO}_{2}-$ and nitrate $\mathrm{NO}_{3}-$, as well as numerous organic substances. Nitrogen is one of the most important biogenic elements; the concentration of its compounds largely determines the biological productivity of a water body. Therefore, the total content of nitrogen compounds can serve as one of the main indicators of the potential eutrophication of water bodies $[2,4,5]$.

The Pskem River, which is located in the Tashkent region of Uzbekistan, in the Syrdarya river basin, was chosen as the object of research. The Pskem River originates from the confluence of the Maidantal and Oygaing Rivers and flows into the Charvak reservoir.

The work used observational data of Pskem Rivers for the concentrations of ammonium nitrogen, nitrite nitrogen, and nitrate nitrogen for the period from 1990 to 2017.

\footnotetext{
*Corresponding author: a.fatxulloyev@tiiame.uz
} 


\section{Methods}

To date, determining the average annual concentration of pollutants in the River flow mainly uses two main methods $[1,6,7,8]$.

In the first method, the calculated value of the average annual concentration is determined without taking into account the water content, as an average arithmetic value for all measured values of concentrations in $\mathrm{j}$-year, that is:

$$
\overline{S_{\mathrm{j}}}=\left(\sum_{i=1}^{n j} S_{j i}\right) / n
$$

There: $\bar{S}_{\mathrm{j}}$ is the number of concentration measurements in the $\mathrm{j}$-th year; $\mathrm{i}$ is number of measurements of concentration in the $\mathrm{j}$-th year; $S_{j i}$ is measured i-th concentration of pollutants in $\mathrm{j}$-th year; $\mathrm{n}$ is number of measurements in the $\mathrm{j}$-th year.

But this technique does not take into account the water content of the river during water sampling and the inequality of the initial series of hydrochemical data. The methodology assumes that the water content of the rivers is the same throughout the time period on the days of sampling. Therefore, this method can only be used when the water consumption at the selected water body is constant throughout the year. Otherwise, the results will be inaccurate. Therefore, in the works of V.A.Shelutko, E.V.Kolesnikova, E.S.Urusova, O.Nasser developed methods for specifying the values of average annual concentrations of pollutants $[5,9,10,11]$.

The second method considers the water content of the river during the sampling period for chemical analysis. The calculated value of the average annual concentration of pollutants is determined as the average value weighted by water consumption:

$$
\bar{S}=\sum_{i=1}^{n j}\left(S_{j i} \times Q_{j i}\right) / \sum_{i=1}^{n j} Q_{j i}
$$

There: $\mathrm{Q}_{j i}$ is the $\mathrm{i}$-th value of water discharge in the $\mathrm{j}$-th year.

In hydroecological calculations, the second method is most widely used, especially for small rivers. This is because water samples in rivers for chemical analysis are not always accompanied by measuring water discharge. In many cases, on rivers where water samples are taken for chemical analysis, water discharge is not measured at all. For many researchers, the difference in the results of the calculation according to the first and second formulas seems insignificant, since earlier in the analysis of other processes, as a rule, in most cases, the average of measurements practically coincided with the actual average value $[3,12,13]$.

Meanwhile, it can be shown that the first method has a rather significant limitation. Indeed, the average annual concentration of pollutants in a given section $\bar{S}_{j}$ in each j-year is determined as the ratio of the annual runoff of pollutants $\left(\mathrm{M}_{p j}\right)$ to the annual volume of water runoff $(\mathrm{Wcj})$, that is:

$$
\bar{S}_{j}=\mathrm{M}_{p j} / \mathrm{W}_{\mathrm{c} j}
$$

In his the turn of the annual runoff of pollutants $\left(\mathrm{M}_{p j}\right)$ through a given section is the sum of discharge $\mathrm{Q}_{p j i}$, that is

$$
\mathrm{M}_{p j}=\sum_{i=1}^{n j} \mathrm{Q}_{p j}
$$

the daily consumption of pollutants is equal to the product: 


$$
Q_{p j}=S_{j i} \times Q_{j i}
$$

There: $S_{j i}$ is the average concentration on the $i$-th day of the $\mathrm{j}$-th year, $Q_{j i}-$ is the water discharge in the given section.

From there

$$
\mathrm{M}_{p j}=\sum_{i=1}^{n j} S_{j i} \times Q_{j i}
$$

The volume of annual water flow through this section:

$$
\mathrm{W}_{\mathrm{c} j}=\sum_{i=1}^{n j} Q_{j i}
$$

Substituting (6) and (7) in formula (3), we obtain formula (2) for calculating the average annual concentration. Thus, the second method, based on the use of formula (2), taking into account the water content of the river, is physically justified. Therefore, calculations by this method give optimal results. Let's take the water consumption constant throughout the year, then from formula (2). We obtain formula (1), the formula for calculating the average annual concentration as the arithmetic mean of the measured concentration values. Really

$$
\bar{S}=\left(Q_{j} \sum_{i=1}^{n j} S_{j i}\right) /\left(n \times Q_{j i}\right)=\sum_{i=1}^{n j} S_{j i} / n
$$

Thus, when calculating the average annual concentration as an arithmetic mean, it is deliberately assumed that water discharge during the year at the object under consideration is constant. In fact, water discharges are extremely variable, and the ability of a river to transport pollutants with its waters changes tens and hundreds of times throughout the year $[1,3]$. Therefore, formula (1), which does not consider the value of water consumption when measuring the concentrations of pollutants, does not reflect the actual value of the average annual concentration.

Figure 1 shows, as an example, the results of calculating the average annual concentration of nitrate, nitrite, ammonium nitrogen, and Figure 2 shows the results of calculating the average annual concentrations of runoff volumes. 


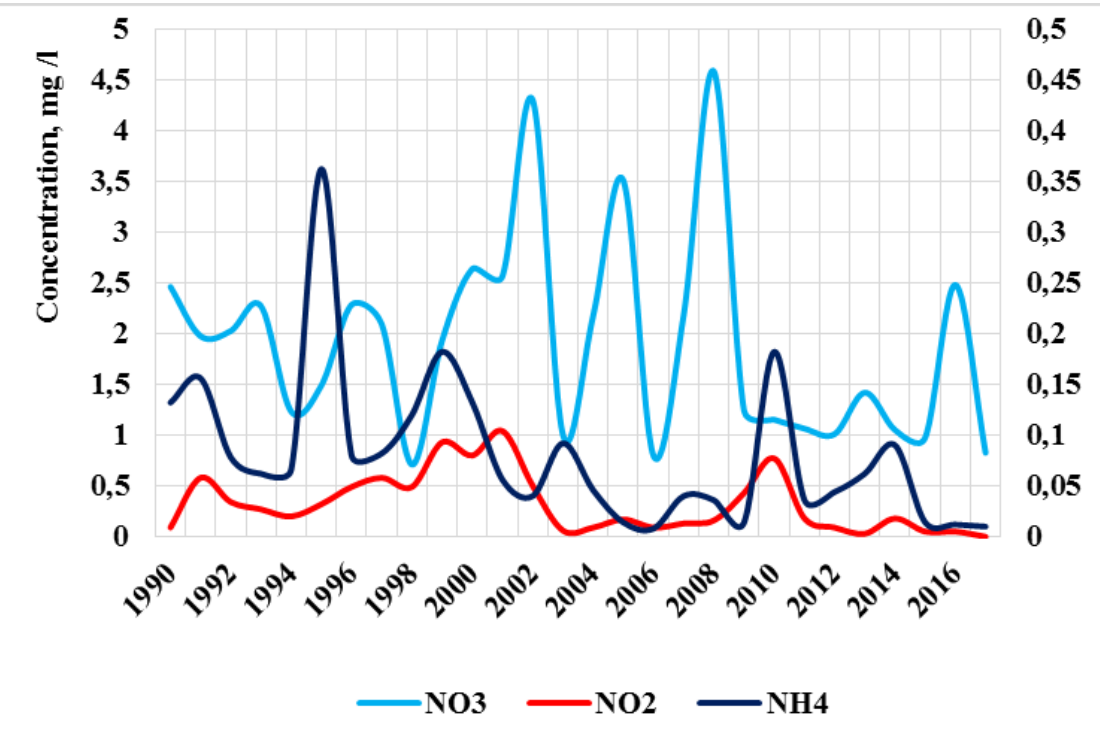

Fig. 1. The results of calculating the average annual concentration of nitrate, nitrite, ammonium nitrogen on the Pskem River - Mullala village (section 01) 1990-2017

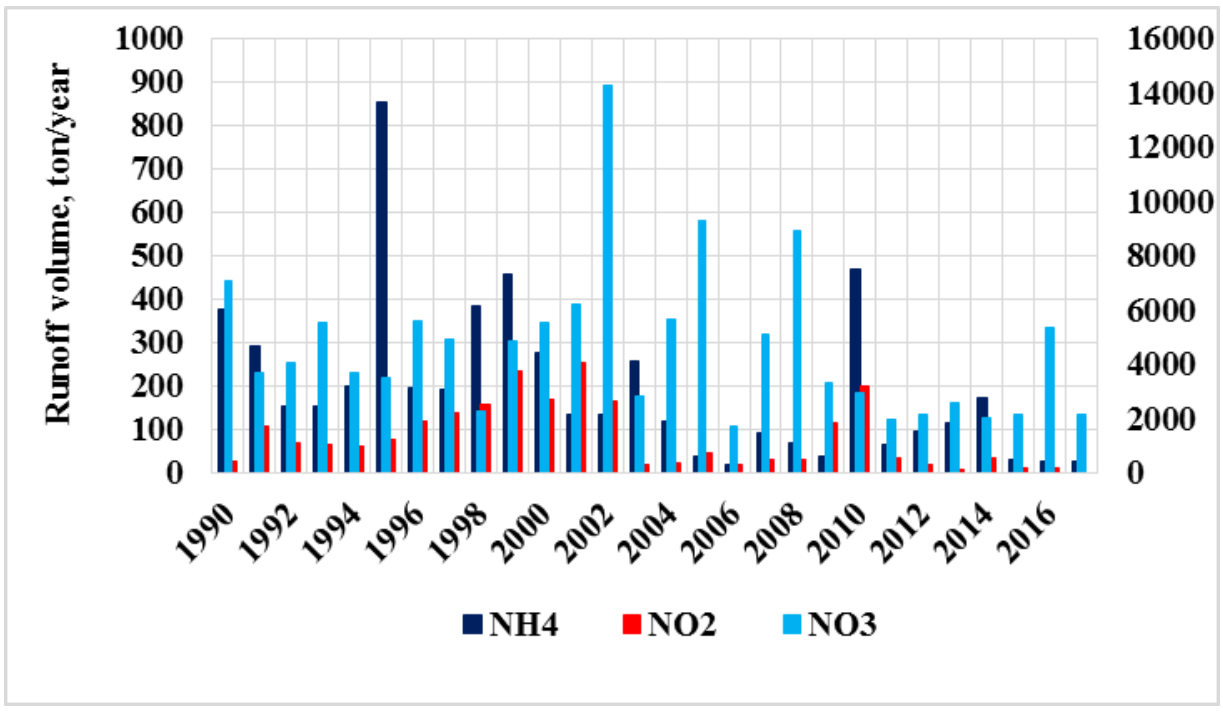

Fig. 2. Average annual values of the concentrations of the runoff volumes of ammonium, nitrate, nitrite nitrogen on the Pskem river - Mullala village (section 01) 1990-2017

To determine the errors in calculating the average annual concentrations, it is first necessary to calculate the average annual concentrations of various forms of nitrogen in the Pskem River using one of the previously listed methods, after which the absolute and relative errors are calculated using formulas (9) and (10).

$$
\Delta_{i}=S_{a i}-S_{b i}
$$




$$
\delta_{i}=\Delta_{i} / S_{b i} \times 100 \%
$$

There: $S_{a i}$ is the average annual concentration of the substance, calculated without considering the water content; $\mathrm{S}_{b i}$ is annual average concentration of the substance, calculated taking into account the water content.

The values $\Delta_{i}$ and $\delta_{i}$ were calculated for each $i$-th year for all observation series.

To calculate the average annual concentration of various nitrogen compounds, taking into account the water content of the Pskem River, the formula (2) is used. The relative and absolute errors obtained without considering the water content were calculated using formulas (9) and (10).

In addition, to more clearly see the difference in the obtained values of average annual concentrations with and without water content, the calculation results are presented in Figure 1.

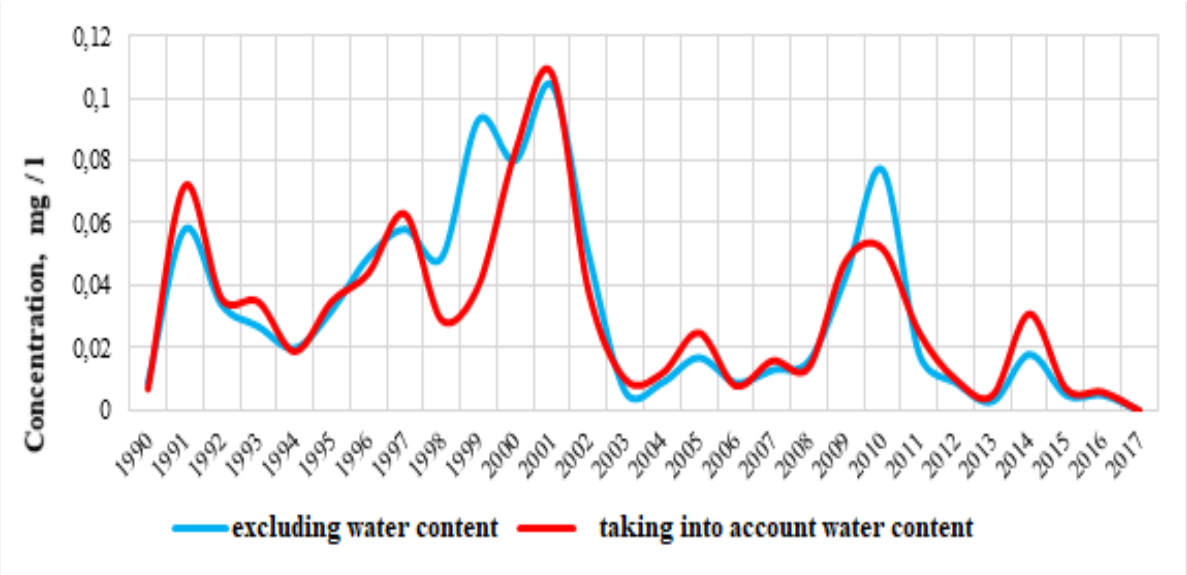

Fig. 3. Average annual concentrations of nitrite nitrogen with and without water content at station 101 point-1217401 of the Pskem river, Mullala village, section 01

For a detailed analysis of the errors in calculating the average annual concentrations, with and without taking into account the water content, empirical curves of the probability of the error values were constructed

\section{Result and Discussion}

Probability curves were constructed using the StokStat 1.2 package on the probability fiber. Figures 4 and 5 shown, as an example, empirical curves of the provision of generalized series of errors in estimating average annual concentrations due to not taking into account the peculiarities of hydrochemical observation series for nitrite nitrogen. 


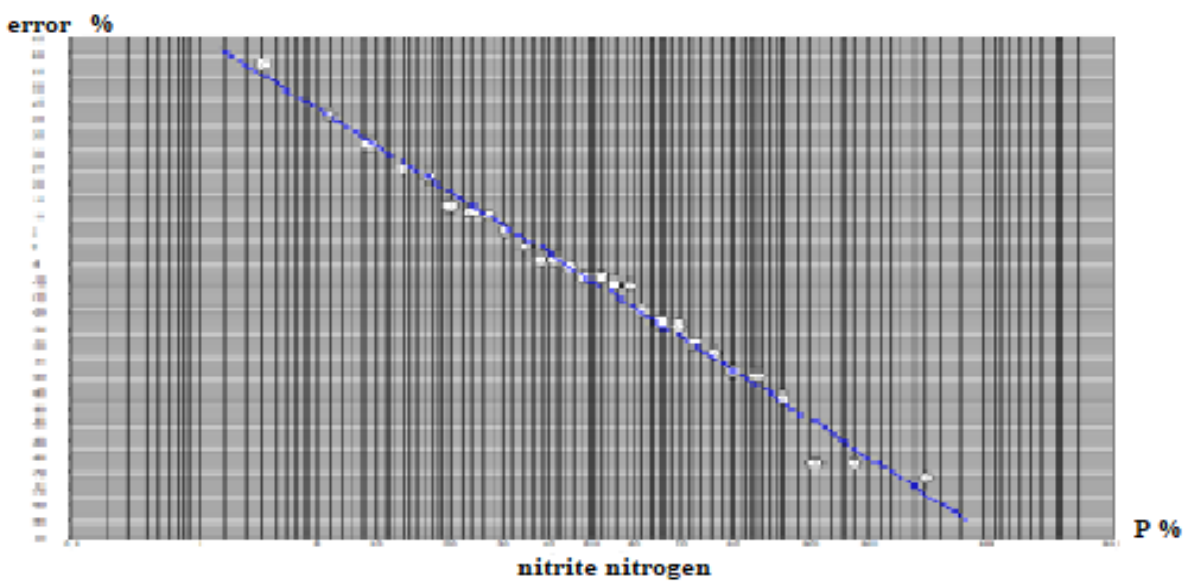

Fig. 4. Empirical curve of provision of generalized series of errors $\delta_{i}(\%)$ for calculating the average annual concentration of nitrite nitrogen without taking into account water content.

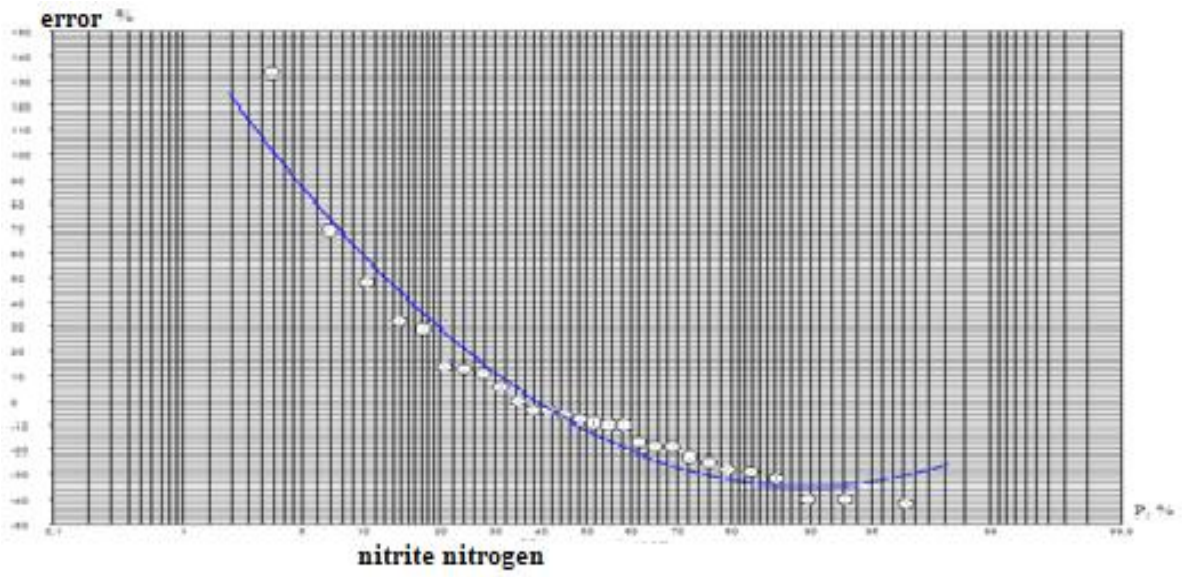

Fig. 5. Empirical curve of provision of generalized series of errors $\delta_{i}(\%)$ for calculating the average annual concentration of nitrite nitrogen, taking into account water content.

Based on the analysis, it follows that at the observation point of the Pskem River, the village of Mullala, post 01 , the value of the relative errors of the average annual concentrations of nitrite nitrogen varies from -42 to $+133 \%$, while the average value is $0.39 \%$. If we do not consider the water content of the river when calculating the average concentrations for the year, then obtained values will significantly exceed the real values of concentrations.

This conclusion is confirmed by the analysis, as in Figure 3 it can be seen that not taking into account the water content overestimates the values of the average annual concentrations. At a time when the water content remained almost unchanged, very small error values are observed. And vice versa, in those years when the water discharge in the Pskem River during the year changed most strongly, the largest values of the calculation error are observed. On small rivers, the water content can vary greatly throughout the year, not accounting for it leads to much larger losses needs.

Thus, in order to obtain a more accurate value of the average annual concentrations, it is still better to take into account the water content for the Pskem River. 


\section{Conclusion}

As a result of the provided research, the following conclusions were obtained:

1. Currently, two methods are mainly used to estimate the average annual concentrations of pollutants in river runoff. The first of them considers the water content of the river during the sampling period for chemical analysis, and the calculated value of the average annual concentration is determined as the average value weighted by the water flow rate. In the second, water content, as the arithmetic mean of all measured values of concentrations.

2. Failure to consider the peculiarities of hydrochemical and hydrological information leads to significant errors in calculating the average annual concentrations and volumes of runoff of pollutants.

3. To reduce the errors in calculating the average annual concentrations of substances in the water, it is necessary to consider the water content of the river during the sampling period. Otherwise, calculation errors can reach from plus $197 \%$ to minus $42 \%$. The longterm average values differ less significantly.

4. It is known that on small rivers, where the water content during the year can be very different, not accounting for it leads to much larger errors. Thus, to obtain a more accurate value of the average annual concentrations, it is still better to consider the water content for the Pskema River.

5. Empirical curves are a fairly good indicator of the state of chemical pollution of rivers and, apparently, must be used in the initial analysis, especially to identify certain significant trends of change.

6. Failure to take into account the water content during the sampling period can lead to significant errors in calculating the average annual and average long-term concentrations, mostly in the direction of exaggeration, which in turn will lead to a similar exaggeration of the volumes of pollutant runoff through a given section. Therefore, it is necessary to use a method for estimating average annual concentrations in all cases, taking into account the water content during the sampling period.

\section{References}

1. Smyzhova E.S., Shelutko V.A. Consideration of the influence of non-equidistance of the initial information on the assessment of biogenic pollution of rivers using the example of the Velikaya river Materials of Intern. scientific-practical conf. "Geographical education and science in Russia: history and current state" BB, (2010)

2. Shelutko V.A., Smyzhova E.S. Dynamics of the runoff of nutrients along the Velikaya river to the Pskov-Peipsi lake № 13, pp. 89-104, (2010)

3. Fatkhulloev A Gafarova A Hamraqulov J 2019 The Importance of Mobile Applications in the Use of Standard Water Measurements International Conference on Information Science and Communications Technologies Applications, Trends and Opportunities ICISCT (2019), doi: 10.1109/ICISCT47635.2019.9011816

4. Shelutko V.A., Kolesnikova E.V. Analysis of errors in calculating the average annual concentrations of pollutants in rivers due to the lack of water content Bulletin of St. Petersburg State University ser 7 № 3, (2008)

5. Shelutko V.A. Methods of processing and analysis of hydrological information Teaching aid. St. Petersburg Petersburg State University, p. 192, (2007)

6. Fatxulloyev A., Gafarova A., Hamroqulov J. Improvement of water accounting for irrigation systems IOP Conference Series: Materials Science and Engineering 1030 012145, (2021), doi:10.1088/1757-899X/1030/1/012145

7. Shelutko V.A., Nasser Othman Urusova E.S. Analysis of the processes of pollution of 
the river Great different forms of nitrogen Bulletin of St Petersburg State University Ser 7 (3), (2014)

8. Fatxulloev A., Gafarova A. Study of the process of cultivation in soil fertile irrigation $\begin{array}{llllll}\text { canals } \quad \text { E3S Web of Conferences } 97 & 05025, & \text { (2019) }\end{array}$ https://doi.org/10.1051/e3sconf/20199705025

9. Arifjanov A., Fatxullaev A. Natural Studies for Forming Stable Channel Sections Journal of Physics: Conference Series 1425(1) 012025, (2020), doi:10.1088/17426596/1425/1/012025

10. Fatxulloyev A., Gafarova A., Otakhonov M., Allayorov D. The hydraulic efficiency of the soil channels IOP Conference Series: Materials Science and Engineering 883(1) 012042 (2020), doi:10.1088/1757-899X/883/1/012042

11. Fatxulloyev A., Abduraimova D., Otakhonov M., Atakulov D., Samiev L. Method designing of open drainages IOP Conference Series: Materials Science and Engineering 883(1) 012047, (2020) doi:10.1088/1757-899X/883/1/012047

12. Fatxulloyev A., Allayorov D., Otakhonov M. Study of hydraulic parameters for concreting channels IOP Conference Series: Earth and Environmental Science 614(1) 012054 (2020), doi:10.1088/1755-1315/614/1/012054 